\title{
THE PATHOLOGY OF OTITIS MEDIA
}

\author{
BY \\ I. FRIEDMANN \\ From the Department of Pathology of the Institute of Laryngology and Otology, London
}

(RECEIVED FOR PUBLICATION NOVEMBER 11, 1955)

Knowledge of the pathology of otitis media is conflicting in spite of the vast amount of relevant literature.

One of the objects of the present investigation has been to re-examine this field in relation to the question as to whether the pathology of otitis media and maistoiditis has changed since the advent of the antibiotics as often suggested. For this purpose bone-chips removed at recent mastoidectomy operations have been studied.

\section{Materials and Methods}

Three hundred and seventy five samples of bone chips removed at mastoidectomy operations were decalcified, embedded in paraffin-wax, and sectioned. Sections were stained with haemotoxylin and eosin, Van-Gieson, Gram, Ziehl-Neelsen, and Masson's trichrome. The periodic-acid-Schiff reaction was used for the demonstration of mucus-secreting cells or glands.

\section{Cases of Acute Mastoiditis}

The number of acute infections was, as expected, fairly small. The pathological changes were, however, intensive and characteristic.

In the early stages the mucosa of the air cells was congested and swollen, lined with flat or cuboidal cells (Fig. 1). The lumen was filled with pus, replaced later by fibrous granulation tissue (Figs. 2 and 3). There was evidence of osteoclastic activity and already, at an early stage about five to 10 days after infection, of intensive formation of new bone (Figs. 3, 4, and 5).

There was great variation in a given specimen and neighbouring mastoid air-cells presented different stages from suppuration to fibroblastic organization and ossification.

In some cases, of streptococcal aetiology, there was considerable haemorrhage and destruction of bone. Equally, an occasional acute case caused by $B$. proteus showed evidence of widespread suppuration.

\section{Cases of Chronic Mastoiditis}

Evidence of inflammatory changes has been noted in 270 cases. In 80 specimens there was no evidence of infection and they were rejected for this study (these were cortical bone chips).

The positive findings were (1) granulation tissue in the bone fragments ; (2) signs of bone reconstruction ; (3) mucosal changes ; (4) aural cholesteatoma ; (5) cholesterol-granuloma.

(1) Granulations when present lay freely, covered the bone fragments, or filled the cells, the antrum, or eroded bone. They consisted of nonspecific inflammatory granulation tissue infiltrated by plasmacytes, lymphocytes and enclosing glandlike structures. The granulations were on the whole identical with the structure of the so-called aural polyp.

(2) There was much evidence of reconstruction of bone indicated by dark-blue staining lines of apposition of various thickness resembling the surface of glaciers (Fig. 6), and irregular cement lines forming an intricate mosaic pattern (Figs. 7 and 8).

(3) The mucosa of the mastoid cells whether oedematous or fibrotic was infiltrated by round cells and frequently lined by ciliated columnar epithelium which formed gland-like structures (Figs. 9 and 10). The "glands" contained mucus giving a positive periodic-acid-Schiff reaction.

(4) Stratified squamous epithelium, lining cholesteatoma cavities, was often seen covering the bone chips (Fig. 11). From the inverted keratinized surface, multiple layers of epidermoid keratinized epithelium were desquamated filling the cholesteatoma cavity proper. Sometimes only fragments of keratinized matter surrounded by giant cells were found (Fig. 12).

(5) Frequently no true epidermoid cholestedtoma was found but only rich deposits of cholesterol crystals surrounded by giant cells embedded in fibrous granulation tissue (Figs. 13 and 14).

\section{Discussion}

It has been suggested that the pathology of otitis media may have undergone some basic 


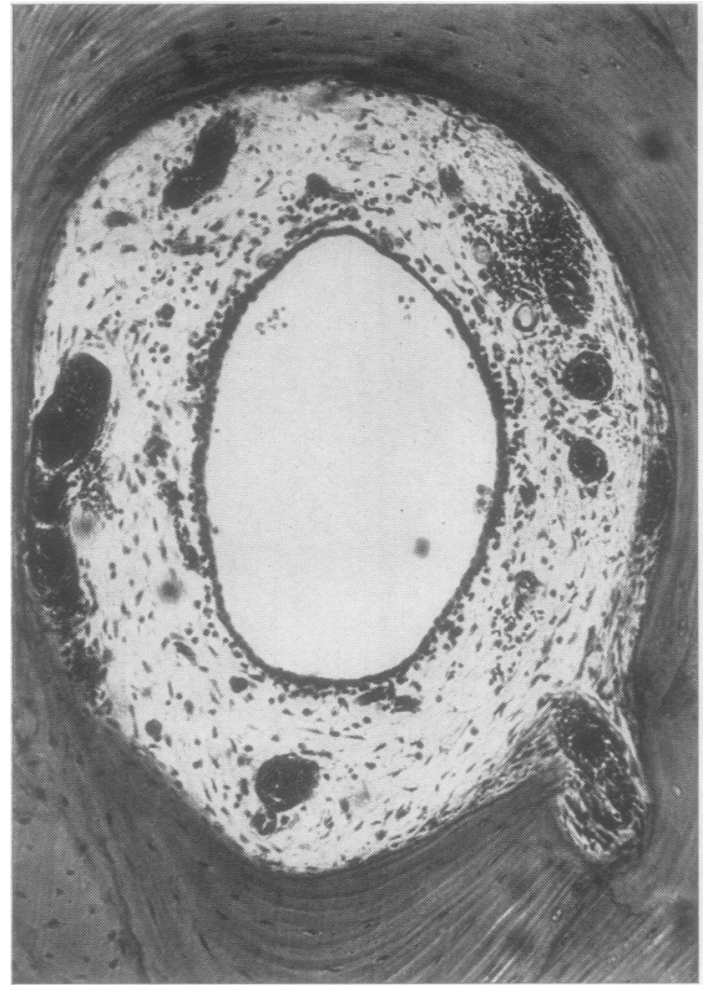

FIG. 1

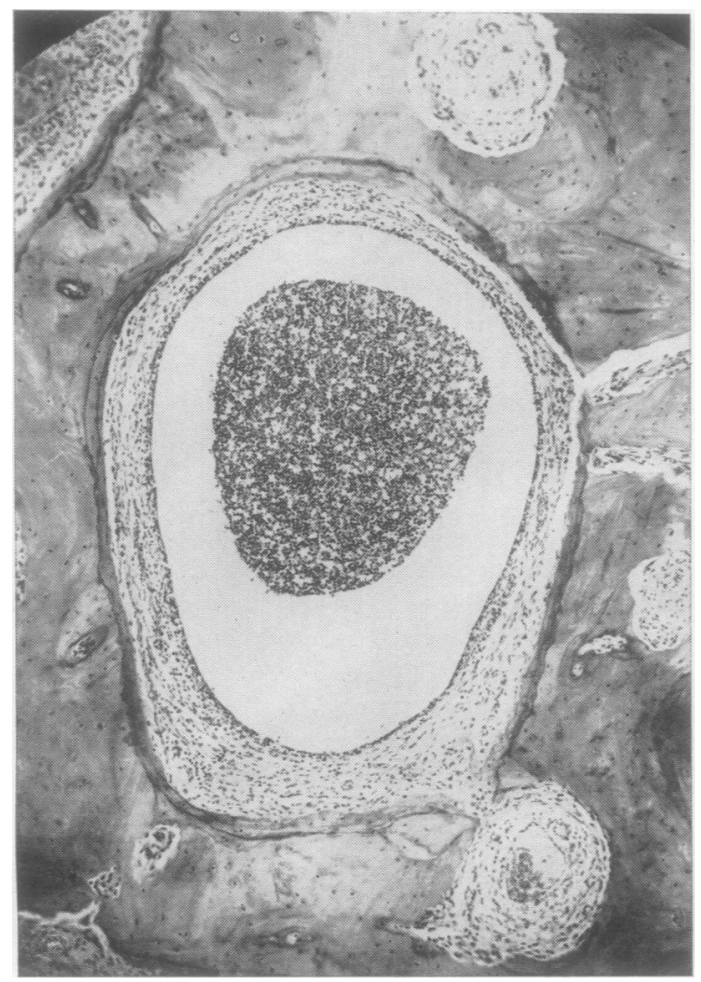

FIG. 2

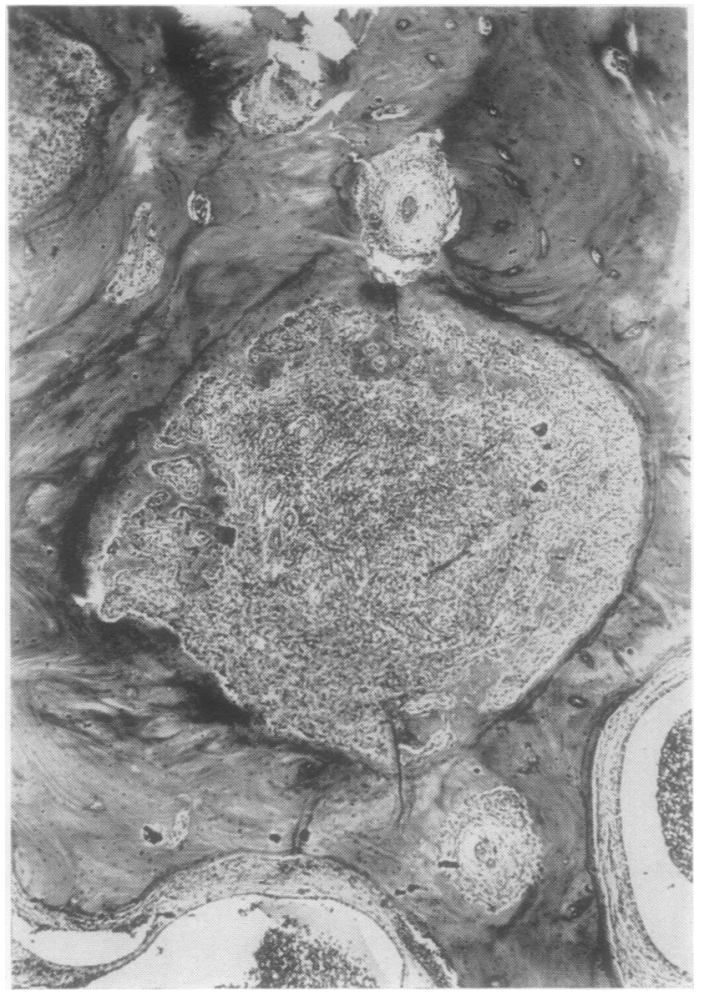

F:G. 3

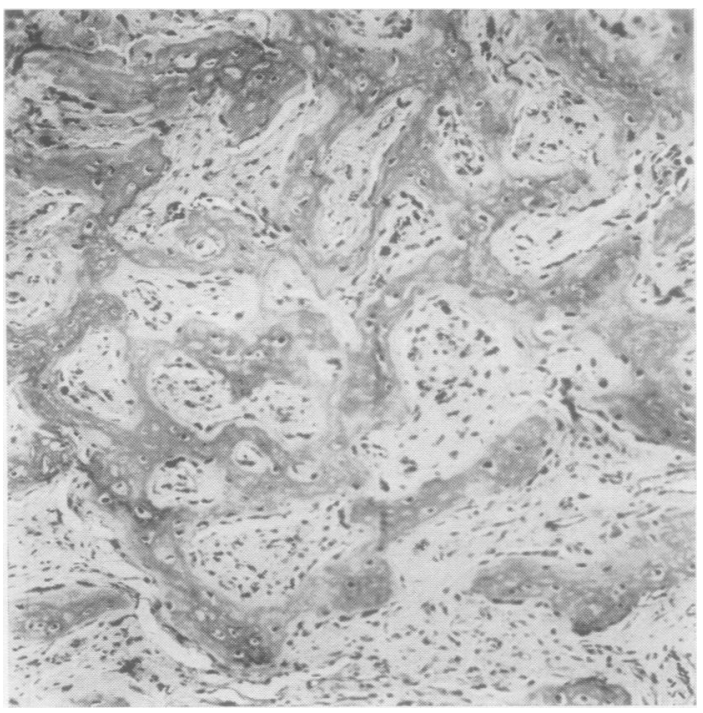

FIG. 4

FIG. 1 (1224 54)-Mastoid cell showing congested mucosa and healthy laminated bone. Haematoxylin and eosin, 150 .

FIG 2 (837 53)-Acute mastoiditis (10 days' history). Note pusfilled mastoid cell, thickened lining. Haematoxylin and eosin, $\times 45$.

FIG. 3.-Neighbouring mastoid cell showing fibrous organization and intensive new-bone formation. Haematoxylin and eosin, 30. As Fig. 2.

FIG. 4 (1582 53).-Acute mastoiditis (14 days' history). Newly formed reticular bone obliterating cell. Haematoxylin and eosin, 60. 
FIG. 5 (120/55).-Acute mastoiditis (10 days'

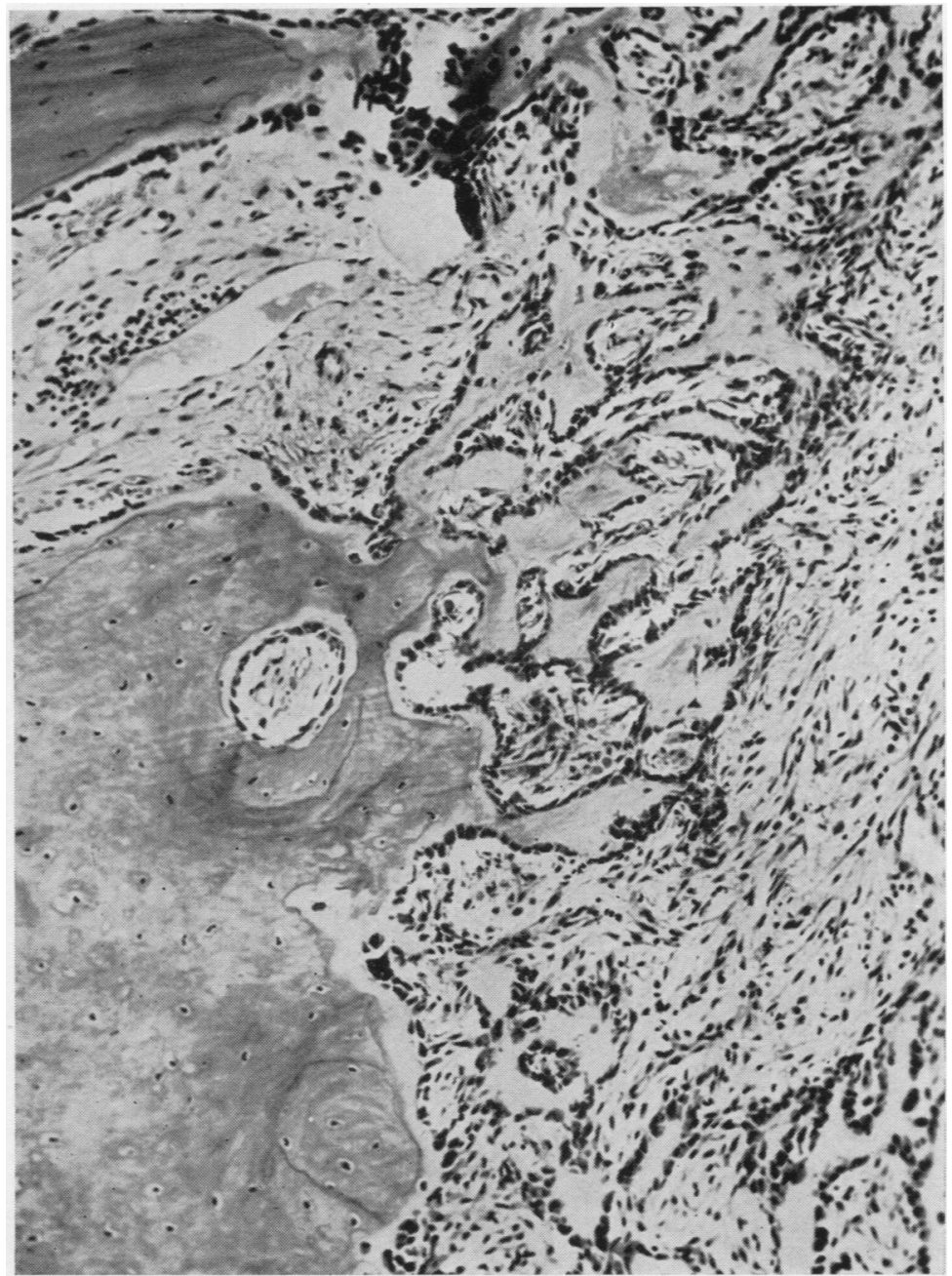

history), showing 'network of reticular bone replacing fibrous granulation tissue. Haematoxylin and eosin $\times 95$.

Fig. 5

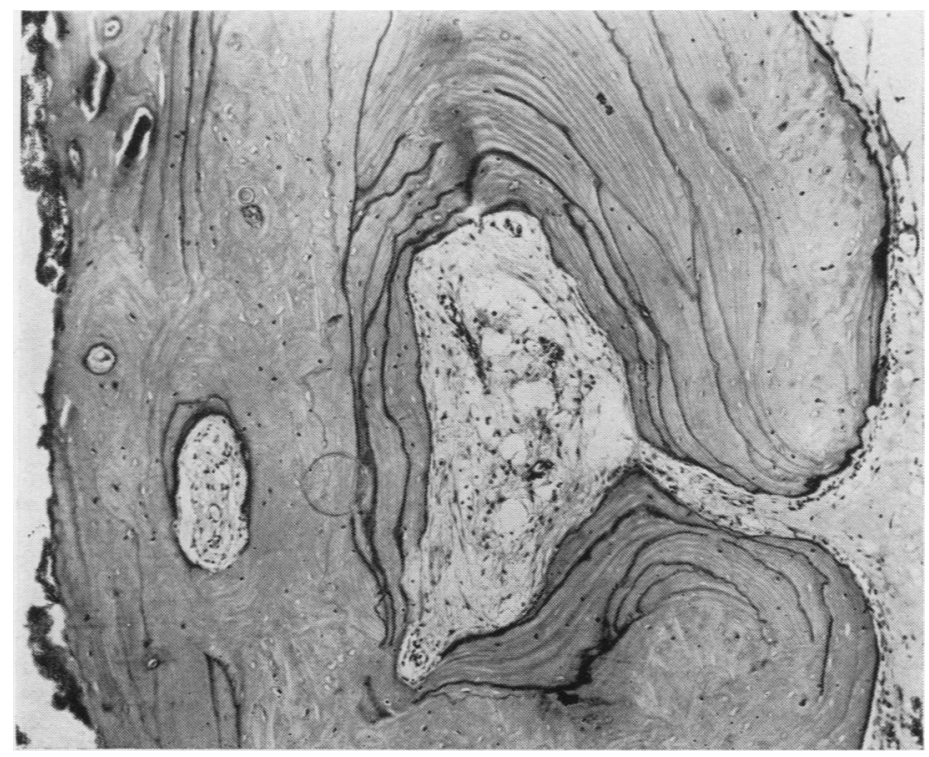

FIG. $6(441 / 53)$. - Glacier-like arrangement of lines of apposition. Haematoxylin and cosin, $\times 52$. 


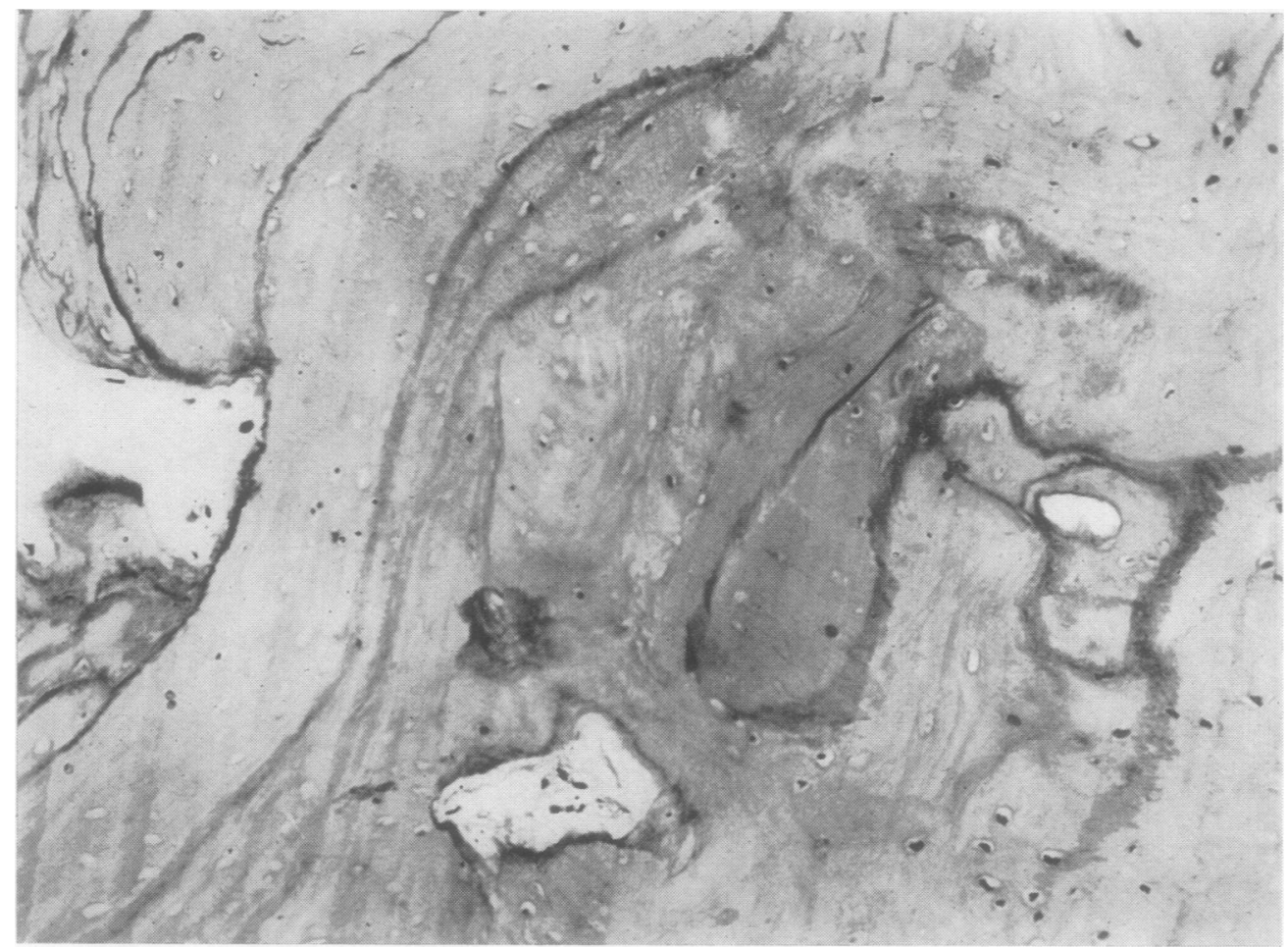

FIG. 7 (1055 53).-Sclerotic bone fragment showing irregular cement lines. Haematoxylin and eosin, 170.

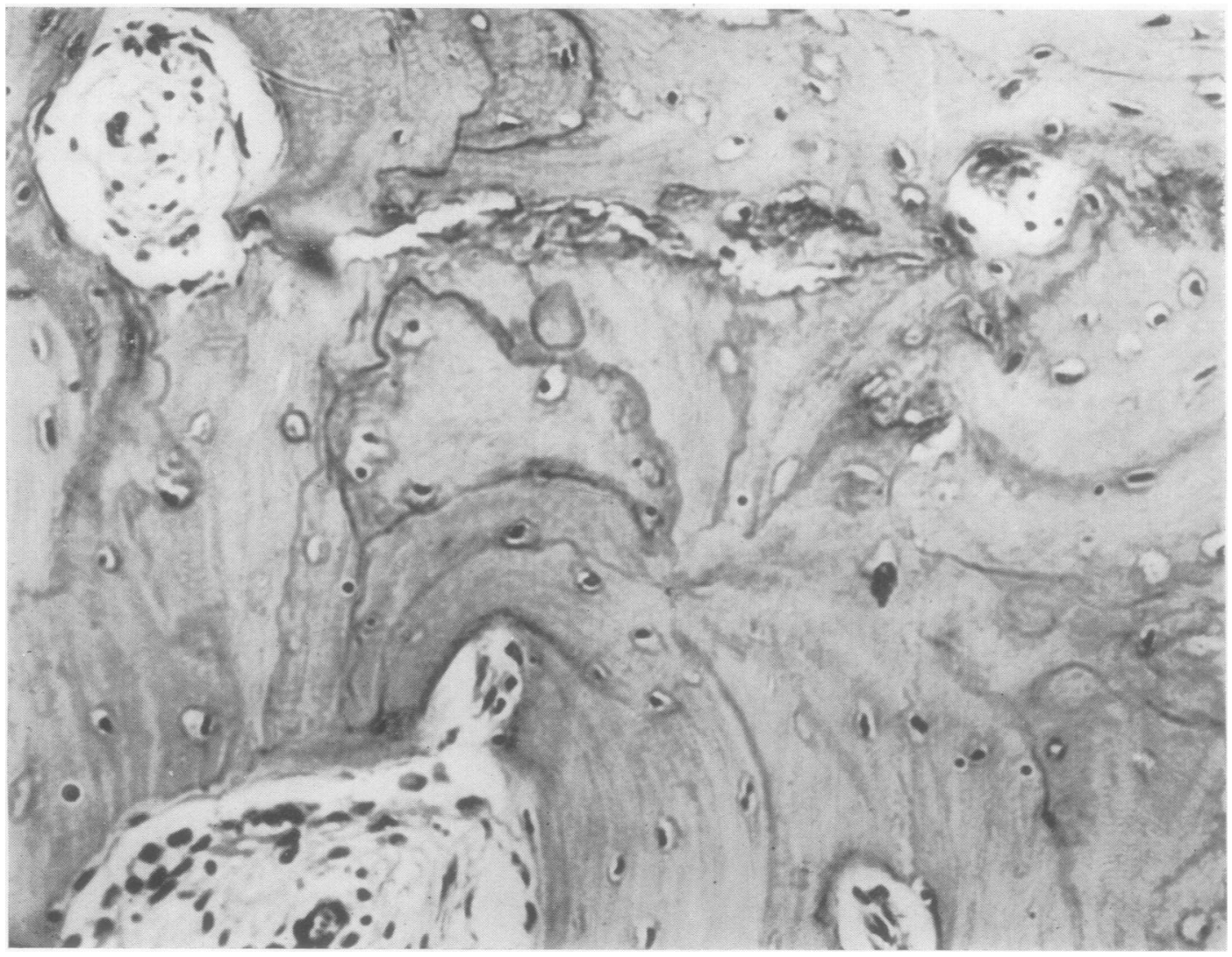

Fig. 8 (1998 54).-Sclerotic bone fragment showing irregular cement lines. Haematoxylin and eosin, $\times 325$. 


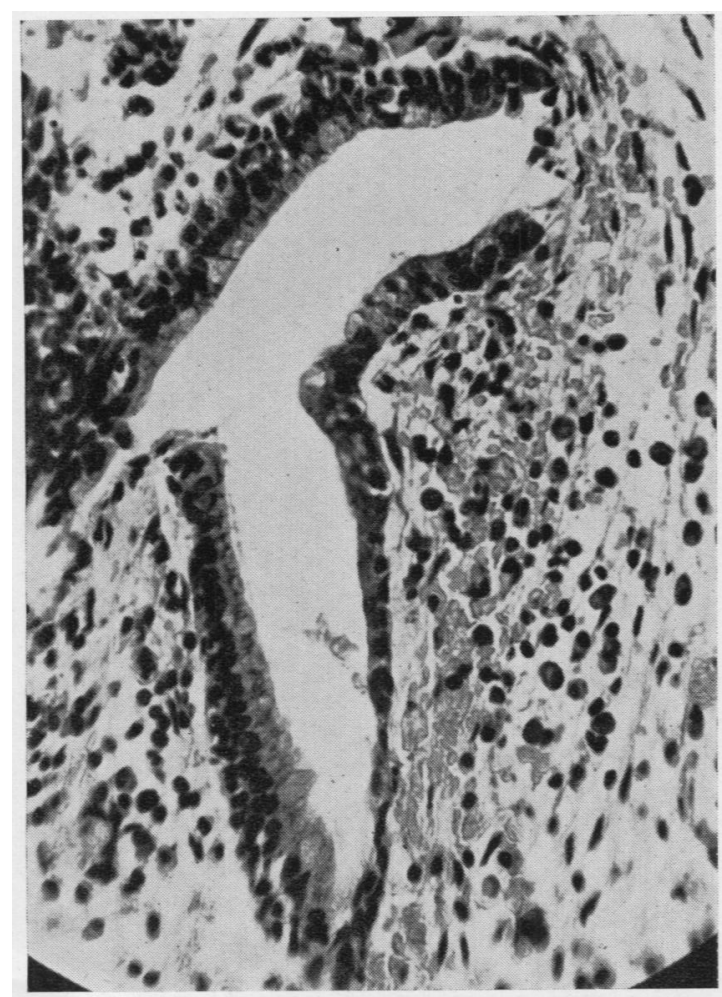

Fig. 9
FIG. $9(181 / 53)$.- Sclerotic bone lined by pseudostratified ciliated columnar epithelium. Haematoxylin and eosin, $\times 490$.

Fig. $10(1693 / 54)$. - Gland in granulation tissue. Haematoxylin and eosin, $\times 400$.

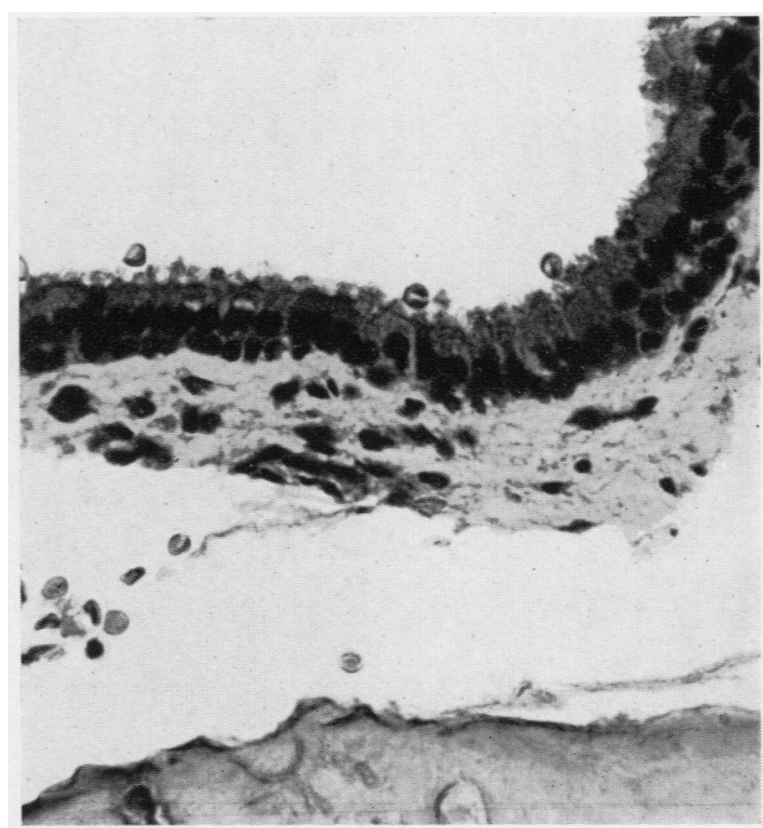

Fig. 10

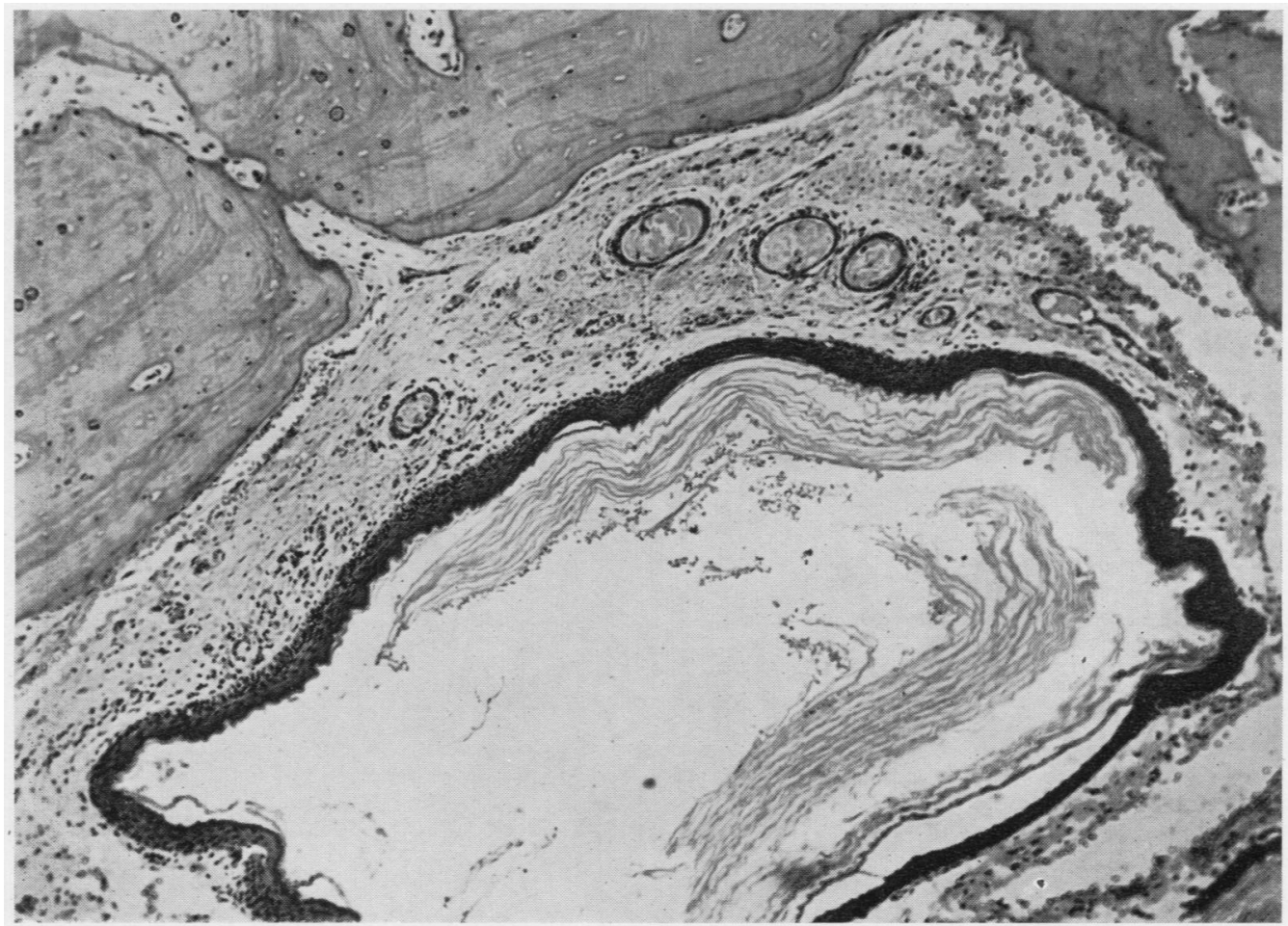

Fig. 11.-Aural cholesteatoma. Note epidermoid squamous epithelium and lamellated keratinized material in the lumen. Haematoxylin and eosin, $\times 72$. 


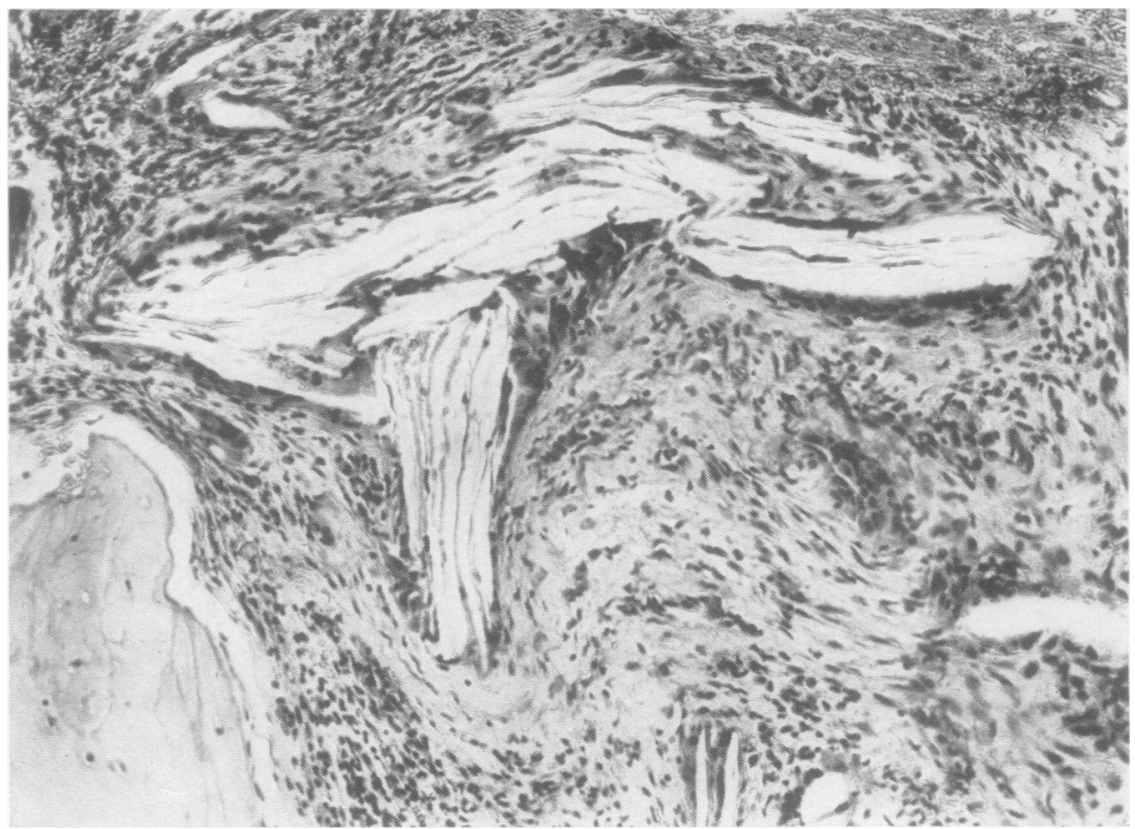

FIG. 12 (279 55).-Chronic inflammatory granulation tissue containing lamellated " cholesteatomatous" material surrounded by foreign-body giant cells. Haematoxylin and eosin, 150 .

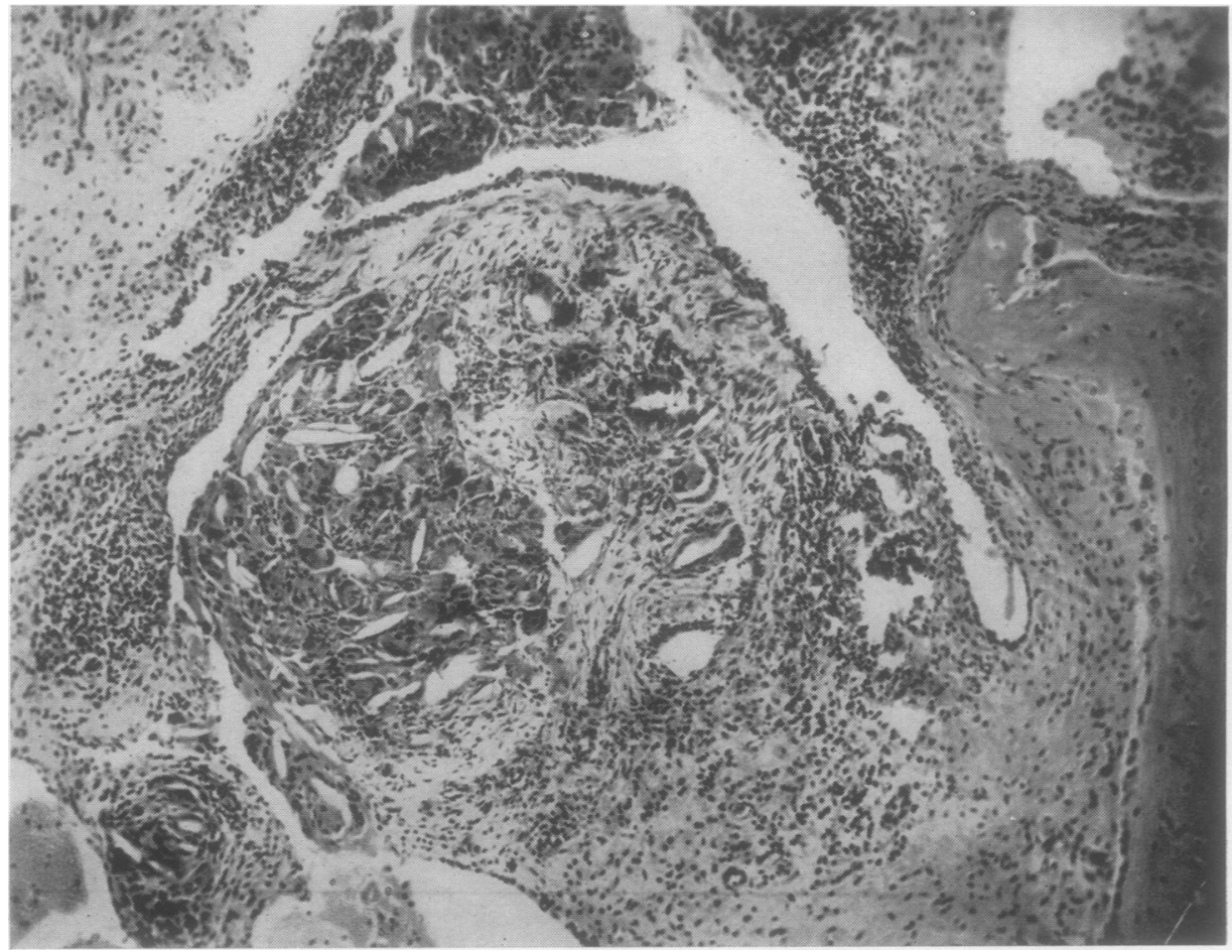

FIG. 13 (1251 53).-Chronic otitis and mastoiditis. Chronic inflammatory granulation tissue with cholesterol granuloma. Haematoxylin and eosin, $\times 72$. 


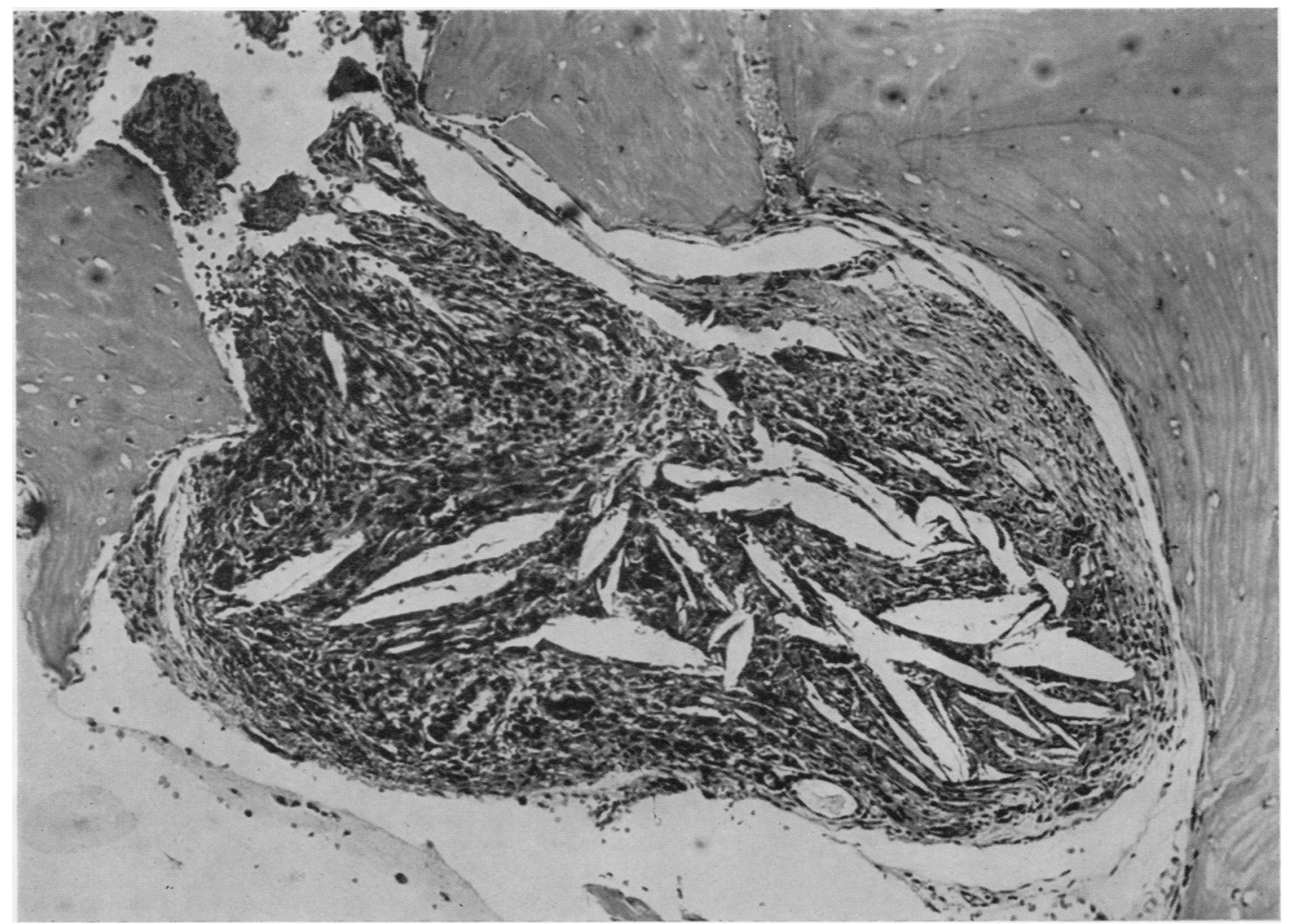

FIG. 14 (865;53).-Chronic otitis and mastoiditis with cholesterol granuloma. Haematoxylin and eosin, $\times 110$.

change in recent years, and that the success of the antibiotic treatment of the disease might have been due in some degree to changes of the pathology of otitis media.

The histopathology of human otitis media and mastoiditis has been studied in detail by, among others, Stewart (1928), who gave a detailed description of the clinical, bacteriological, and histological conditions found in 50 cases of acute mastoiditis. Stewart's material consisted of bone-chips of diseased tissue removed by the Schwartze operation. At about the same time Lange (1928) examined about 100 temporal bones showing various stages of the disease. Both authors agree in their description of the pathological changes in the mastoid cell.

From the present investigations it can be stated that my observations do not differ fundamentally from those of Stewart and Lange. Nevertheless, some of my principal findings merit discussion as their significance has not been fully appreciated (Watkyn-Thomas, 1953).

\section{Bone Formation and Bone Reconstruction}

Evidence has been presented in this paper first of all of conspicuous new bone formation in acute and chronic mastoiditis. This was found in almost every instance of acute mastoiditis. Equally, in bone-chips obtained from mastoidectomy operations for chronic otitis new bone formation and signs of bone reconstruction occurred regularly.

An interesting feature of the bone-fragments in chronic otitis was the bizarre irregularity of the cement lines which produced a mosaic-like pattern resembling that found in Paget's disease. This is evidence of bone reconstruction developing in the course of infection and leading to osteosclerosis.

This pattern is sufficiently characteristic to assist in the differentiation of sclerotic bone from healthy compact bone; ceteris paribus in the differentiation of a sclerotic mastoid process rendered acellular through infection from a congenital compact or ivory mastoid process with intact Haversian systems in the latter. 
In the present studies, the controversial problem of pneumatization of the human mastoid process has only been touched upon. Experimental evidence (Opheim, 1944 ; Friedmann, 1955a and b), and the bone changes in acute and chronic mastoiditis of man suggest that the conversion of a pneumatized mastoid process into a sclerotic one may well be a consequence of infection.

\section{Mucosal Changes}

Two significant mucosal changes were noted in chronic otitis media. The lining covering the thickened fibrous stroma infiltrated by inflammatory cells has often become a more highly differentiated columnar type, forming gland-like structures which produced P. A. S. positive mucus.

The conception of a mucous membrane lining the mastoid cells is not generally accepted, as normally it lacks some of the properties of the typical mucous membrane found in glands and secretory epithelium.

Many observers deny the presence of glands in the mastoid lining. Ojala (1950) in his material found only one instance in which gland-like cavities were present in the subepithelial tissue. They were lined by stratified high cylindrical epithelium consisting almost entirely of goblet cells.

As shown here, under inflammatory conditions at any rate, a true mucous membrane may develop lined by a mucus-secreting epithelium forming gland-like structures.

\section{Cholesteatoma}

The flattened cellular lining was frequently replaced by stratified squamous epithelium leading to the formation of the so-called aural cholesteatoma. It is generally accepted that the pathogenesis of true aural cholesteatoma rests upon the presence of a stratified squamous epithelium in the middle ear cleft (Tumarkin, 1954). It is the origin of this squamous epithelium that is still in doubt. Experimental evidence has been presented (Friedmann, 1955b) that migration or extension of the stratified squamous epithelium from the external auditory meatus, or from the drum, can produce the effects associated with true epidermoid aural cholesteatoma of man (deposition of lamellated, desquamated, keratinized matter). This is probably the most frequent mechanism of the development of aural cholesteatoma in man.

\section{Cholesterol Granuloma}

Besides the true epidermoid aural cholesteatoma, in some cases clinically so diagnosed, the sections showed a basically different but characteristic pic- ture. There were cholesterol deposits surrounded by foreign-body giant-cells in the granulation tissue filling the middle ear. At operation these structures, here called "cholesterol-granuloma" may often be mistaken for aural cholesteatoma. Such cholesterol deposits however, occur also at other sites of chronic inflammation and/or haemorrhage (Stewart, 1915; Dible and Davie, 1945) and it may be assumed that their presence in the infected middle ear cleft is directly connected with the infection. Stratified squamous epithelium, however, has no role in its formation.

\section{Summary}

The pathology of otitis media is described.

There is no evidence to support the suggestion that the basic pathology of otitis media has changed in the post-penicillin era, when compared with the findings of authors reported in the prepenicillin era.

Infection takes place in the mucosa of the ear which is very susceptible to infection by certain organisms. Bone formation sets in early and, with progression to the chronic phase, there is considerable reconstruction of the bone recognizable by an irregular mosaic pattern of cement lines or lines of apposition. The mucosal lining reverts either to a columnar respiratory type, when it forms gland-like structures, or may be replaced by a stratified squamous epithelium forming the pathological substrate of aural cholesteatoma. Cholesterol deposits surrounded by foreign body giant cells are common in chronic mastoiditis. Such structures, best called cholesterol-granuloma, should not be mistaken for the true epidermoid cholesteatoma.

It is suggested that the hyperplastic mucosal and osteoplastic processes observed are not the cause, but the outcome, of otitis.

I wish to thank the staff of the Royal Nationa Throat. Nose and Ear Hospital and to the sisters of the operating theatres for their kind co-operation. My special thanks are due to Mr. E. S. Bird and Miss V. Shepherd for the sections and to Mr. D. Connolly for the photography.

\section{REFERENCES}

Dible, J. H., and Davie, T. B. (1945). Pathology, 2nd ed., p. 28 Churchill, London.

Friedmann, I. (1955a). J. Larvng., 69, 27.

- (1955b). Ibid.,69, 598 .

Lange, W. (1928). Z. Hals-, Nasen-u. Ohrenheilk., 20, 3.

Ojala, L. (1950). Acta oto-laryng. (Stockh.), Suppi. 86.

Opheim, O. (1944). Ibid., Suppl. 54.

Stewart, J. P. (1928). J. Laryng., 43, 689.

Stewart. M. J. (1915) J. Path. Bact. 19, 305

Tumarkin, A. (1954). In Modern Trends in Diseases of the Ear, Nose and Throat, ed. M. Fllis, p. 153. Butterworth. London.

Watkyn-Thomas, F. W (1953). Diseases of the Throat, Nose and Ear, pp. 688,716,717. Lewis, London. 